\title{
Aminoglucósidos-aminociclitoles: Características estructurales y nuevos aspectos sobre su resistencia
}

SERGIO MELLA M., MARCELA SEPÚLVEDA A., GERARDO GONZÁLEZ R., HELIA BELLOT., MARIANA DOMÍNGUEZ Y., RAÚL ZEMELMAN Z. y CÉSAR RAMÍREZ G.

\section{Aminoglycosides-aminocyclitols: Structural characteristics and new aspects on resistance}

The aminoglycoside-aminocyclitol antibiotics constitute one of the antibacterial agent families with greater activity upon aerobic Gram-negative bacilli. These compounds are formed by the combination of one amino-cyclic alcohol (aminocyclitol) and aminosaccharides (aminoglycosides) linked by glycosidic bonds. The strong bactericidal activity exhibited for these compounds is not only explained by their ability to inhibit the protein synthesis, but also by pleiotropic effect altering the permeability of cytoplasmatic membrane. The penetration of these antibiotics to the bacterial cells is mediated by three well defined phases, being the two latest dependant of the proton-motive force. This fact explains that this kind of compounds have no antibacterial activity upon anaerobic bacteria. Bacterial resistance to aminoglycosides is mainly due to aminoglycoside-modifying enzymes (AME), which are commonly encoded by extrachromosomal genetic elements as are plasmids and transposons. Nevertheless, new mechanisms of resistance and genetic elements participating in the resistance to these compounds have been identified. Thus, recently the methylation of the 16S rRNA binding the aminoglycosides has been described. On the other hand, the gene cassettes acquire an increasing importance, because they can host a varied of families of antibiotic resistance genes, including the aminoglycoside-aminocyclitols. These gene cassettes are associated to integrons, which are able to integrate and express these antibiotic resistance determinants.

Key words: Aminoglycosides; Resistance; Integron.

Palabras claves: Aminoglucósidos; Resistencia; Integrón.

\section{Introducción}

Los antibióticos aminoglucósidos-aminociclitoles constituyen un grupo de agentes antibacterianos con interesantes propiedades para el tratamiento de infecciones bacterianas, particularmente aquellas producidas por bacilos gramnegativos aeróbicos ${ }^{1}$. El descubrimiento de la estreptomicina en 1944 por Waksman y col a partir de cultivos de Streptomyces griseus constituyó un avance médico trascendente, fundamentalmente por su actividad antituberculosa ${ }^{2,3}$. A partir de esa fecha, se ha obtenido un número importante de compuestos de esta familia, ya sea por síntesis de origen natural (kanamicina, gentamicina $y$ tobramicina) o por modificaciones químicas de los compuestos originales con el fin de mejorar sus propiedades farmacocinéticas, toxicológicas

Universidad de Concepción:

Departamento de Medicina Interna, Facultad de Medicina (SMM, MSA)

Laboratorio de Antibióticos, Departamento de Microbiología, Facultad de Ciencias Biológicas (GGR, HBT, MDY, CRG)

Universidad San Sebastián, Concepción: Facultad de Ciencias Biológicas y Tecnológicas (RZZ)

Hospital Naval de Talcahuano, Sección Infectología (SMM)

Financiamiento: Proyectos FONDECYT 1000352 y 1020454

Recibido: 16 marzo 2004

Aceptado: 7 abril 2004 
y/o microbiológicas (dibekacina, amikacina, netilmicina y arbekacina $)^{4-6}$.

Los antibacterianos aminoglucósidosaminociclitoles despliegan una potente acción bactericida, reconociendo a la inhibición de la síntesis proteica como el mecanismo de acción tradicional de estos compuestos. Sin embargo, existe información sobre un efecto bactericida más amplio y multifactorial ${ }^{7,8}$.

Aunque la administración de estos antibacterianos presenta una potencial nefrotoxicidad y ototoxicidad, el estudio de las propiedades farmacodinámicas y microbiológicas de estos fármacos ha permitido su utilización en dosis única; existiendo al momento una interesante experiencia con este esquema de dosificación ${ }^{10-12}$.

En este artículo se analiza la estructura química básica de los aminoglucósidos y su agrupación de acuerdo a las principales características químicas. Además se informa sobre algunas de sus propiedades microbiológicas y sobre nuevos aspectos de la resistencia bacteriana a estos compuestos.

\section{Estructura química básica}

En algunos artículos de revisión acerca de estos agentes antibacterianos es posible encontrar algunos errores sobre la estructura química que ellos poseen ${ }^{13-15}$. Los antimicrobianos aminoglucósidos-aminoclitoles están constituidos por la combinación de dos tipos de compuestos químicos:

- azúcares no aminados (glucósidos) o aminados (aminoglucósidos).
- alcoholes cíclicos no aminados (ciclitoles) o aminados (aminociclitoles).

Las diferentes posibilidades de combinación de estas moléculas aromáticas en los antibacterianos de esta familia son:

- azúcar: aminoglucósido; ciclitol: aminociclitol; ejemplo gentamicina

- azúcar: glucósido; ciclitol: aminociclitol; ejemplo: espectinomicina

- azúcar: aminoglucósido; ciclitol: ciclitol no aminado; ejemplo: kasugamicina

Los antibacterianos característicos de esta familia y de importancia en clínica, estreptomicina, gentamicina y amikacina, pertenecen al primer subgrupo: aminoglucósido-aminociclitol (Figura 1), siendo este el nombre químicamente correcto de estas moléculas ${ }^{16-18}$. Al observar la estructura química de este subgrupo, puede evidenciarse que el término aminoglucósido identifica sólo al componente glucosídico de los subgrupos 1 y 3, pero no al ciclitol o al glucósido no aminado. De hecho, espectinomicina, la cual posee un anillo aminociclitol pero no presenta aminoazúcares ni enlaces glucosídicos, podría considerarse como una molécula atípica dentro de esta familia ${ }^{1,11,13}$.

Una vez establecido el concepto sobre la estructura química de estas moléculas y para efectos prácticos, dado su amplio uso en clínica, se mantendrá el término "aminoglucósido" para referirse a los fármacos incluidos en esta familia.

\section{Unión química entre azúcares y ciclitoles}

La unión glucosídica entre azúcares y ciclitoles es producto de la deshidratación de dos grupos

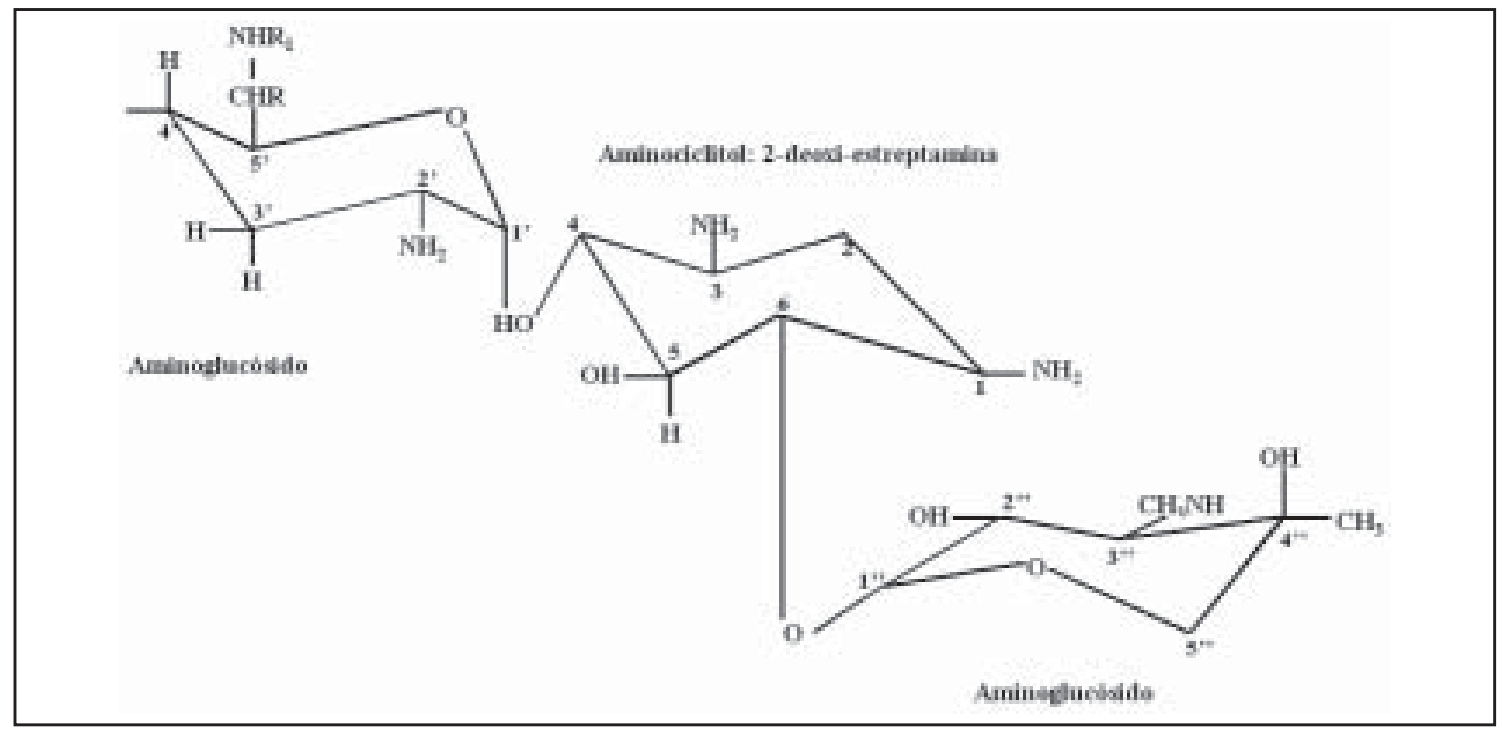

Figura 1. Estructura de un aminoglucósido-aminociclitol. 
de hidroxilos adyacentes, según se muestra en esta reacción:

aminoglucósido-OH $+\mathrm{OH}$-aminociclitol $\rightarrow$ aminoglucósido-O-aminociclitol $+\mathrm{HOH}$

De esta forma, los grupos hidroxilos que originan este enlace pueden tener diferentes posiciones en la molécula de ciclitol. Así, algunos grupos de aminoglucósidos se clasifican de acuerdo a la posición de los grupos reaccionantes, como por ejemplo la 4,62-deoxiestreptamina. En este caso particular los números 4 y 6 indican que la unión glucosídica se ha formado por deshidratación de los radicales $\mathrm{OH}^{-}$de los carbonos 4 y 6 del ciclitol, según se observa en la Figura 1. Para estreptomicina el aminociclitol central es estreptidina mientras que para el resto del grupo es 2-deoxiestreptamina ${ }^{1,13}$. La Tabla 1 muestra la agrupación de los aminoglicósidos basada en el tipo de glucósido y de ciclitol, en el número de moléculas de glucósidos y en las posiciones de las uniones glucosídicas. Aunque no existe un completo conocimiento sobre la relación estructura-actividad de estos compuestos, la remoción de grupos hidroxilos y/o aminos resultaría en una concomitante pérdida de actividad antibacteriana y toxicidad ${ }^{1,6,10}$.

Las propiedades generales de estos compues- tos son ampliamente conocidas; a continuación se analizan algunas de ellas que derivan de los aspectos estructurales antes discutidos.

\section{Propiedades generales de los aminoglucósidos}

Por su carácter policatiónico, los antimicrobianos aminoglucósidos son muy solubles en agua, estables en el medio ambiente y presentan una absorción gastrointestinal menor a $1 \%{ }^{1,4,5,13}$. Debido a esta característica, penetran escasamente la barrera hematoencefálica y, por lo tanto, no alcanzan concentraciones terapéuticamente útiles en el LCR y meninges; similar situación se presenta en el líquido prostático y su penetración en el parénquima pulmonar también parece ser reducida ${ }^{1,4-6,9,19}$.

El ingreso de estos antimicrobianos a las células bacterianas ocurre mediante tres fases bien definidas: Fase de unión iónica superficial, que consiste en una unión iónica no dependiente de energía. En bacterias gramnegativas, los residuos de la molécula de aminoglucósido cargada positivamente se unen a los residuos del lipopolisacárido (LPS) con carga negativa, a las cabezas polares de los fosfolípidos y a proteínas de la membrana externa. Debe recordarse que dos moléculas de LPS se encuentran unidas a un ión $\mathrm{Mg}^{++}$, lo cual estabiliza al LPS y a la membrana

Tabla 1. Principales grupos de antimicrobianos aminoglucósidos

\begin{tabular}{|c|c|c|c|}
\hline $\begin{array}{l}\text { Grupos } \\
\text { principales }\end{array}$ & Relación ciclitol & Representantes & Azúcar/ciclitol \\
\hline \multirow{10}{*}{$\begin{array}{l}\text { Aminoglucósido } \\
\text { aminociclitol }\end{array}$} & Estreptidina & Estreptomicina & $2: 1$ \\
\hline & \multirow[t]{3}{*}{ 4,5 2-deoxiestreptamina } & Neomicinas, paromomicinas & $3: 1$ \\
\hline & & ribostamicina, butirosina & $2: 1$ \\
\hline & & Lividomicina A & $4: 1$ \\
\hline & \multirow[t]{2}{*}{ 4,6 2- deoxiestreptamina } & $\begin{array}{l}\text { Kanamicina, gentamicina, } \\
\text { tobramicina, amikacina, }\end{array}$ & \\
\hline & & $\begin{array}{l}\text { dibekacina, sisomicina, } \\
\text { netilmicina, 5-episisomicina, } \\
\text { verdamicina, isepamicina }\end{array}$ & $2: 1$ \\
\hline & 4,2 deoxiestreptamina & Apramicina & $1: 1$ \\
\hline & 5,2 deoxiestreptamina & Higromicina & $2: 1$ \\
\hline & 2-deoxi inosamina & Inosamicina & $2: 1$ \\
\hline & Fortamina & $\begin{array}{l}\text { Fortimicina, sannamicina } \\
\text { astromicina, dactimicina }\end{array}$ & $1: 1$ \\
\hline $\begin{array}{l}\text { Glucósido } \\
\text { aminociclitol }\end{array}$ & Actinamina & Espectinomicina & $1: 1$ \\
\hline $\begin{array}{l}\text { Aminoglucósido } \\
\text { ciclitol }\end{array}$ & Hexahidrociclohexano & Kasugamicina & $1: 1$ \\
\hline
\end{tabular}


externa, otorgándole cierto grado de impermeabilidad. Se ha planteado clásicamente que la penetración celular de la molécula de aminoglucósido a través de la membrana externa de bacterias gramnegativas es por porinas; sin embargo, no existe consenso sobre este aspecto, ya que algunos autores señalan la existencia de otros mecanismos, principalmente debido al tamaño que presentan estas moléculas $(1,8 \times 1,0 \times 1,0 \mathrm{~nm})^{6,20-26}$. Se ha planteado que la interacción entre el aminoglucósido y cationes divalentes del LPS $\left(\mathrm{Mg}^{++}\right)$produciría una alteración de la membrana externa, aumentando su permeabilidad. Este hecho ha dado origen al concepto de "autopenetración" 22,26 .

Después de la primera fase, el ingreso de los aminoglucósidos a través de la membrana citoplasmática puede ser dividido en dos etapas, ambas dependientes de energía:

Fase 1 dependiente de energía. La fuente de energía es la fuerza protón motriz (FPM), generada por la salida de protones durante el transporte electrónico en la cadena respiratoria. Este fenómeno ocurre en la membrana citoplasmática donde la penetración de este compuesto es favorecido por la diferencia de carga eléctrica dada por la FPM (medio extracelular más electropositivo que el citoplasma). Por sus características fisicoquímicas, esta fase puede ser bloqueada por inhibidores del transporte electrónico y de la fosforilación oxidativa ${ }^{6,11}$.

Fase 2 dependiente de energía. En ésta se produciría una entrada masiva del antimicrobiano cuyo mecanismo íntimo es desconocido, pero podría estar facilitado por la presencia de canales inespecíficos en la membrana citoplasmática, producidos por "péptidos aberrantes" que se unen a ella y que son sintetizados como producto de la acción inicial de los aminoglucósidos sobre el ribosoma bacteriano $0^{6,8,13}$.

La actividad antimicrobiana de estos fármacos disminuye considerablemente en condiciones de bajo potencial de óxido-reducción o de baja tensión de oxígeno. Esto se explica porque en anaerobiosis no existe liberación de $\mathrm{H}^{+}$al medio externo, por lo que no se establece el gradiente de protones (FPM) que promueve la entrada de estos antibacterianos al interior de la célula bacteriana. Esto se comprobó al ensayar la CIM bajo condiciones aeróbicas y anaeróbicas, determinándose una fuerte disminución en la actividad antibacteriana en esta última situación ${ }^{11}$.

\section{Mecanismos de acción antimicrobiana}

Uno de los aspectos más interesantes de la actividad microbiológica de los aminoglucósidos es su elevada actividad bactericida. Así, en estudios cinéticos se ha demostrado que se produce muerte bacteriana de Escherichia coli in vitro antes de los 60 minutos, cuando es sometida a concentraciones bactericidas de gentamicina y amikacina. En condiciones similares, los antimicrobianos $\beta$-lactámicos (ej. cefotaxima) producen la muerte bacteriana en aproximadamente 240 minutos $^{27}$. En este contexto y dado que hay una serie de moléculas que básicamente también inhiben la síntesis proteica, pero que ejercen fundamentalmente un efecto bacteriostático, se ha planteado una interesante hipótesis sobre el mecanismo de acción bactericida de estos agentes, debiéndose enfatizar que el mecanismo último y final de su efecto letal no ha sido totalmente establecido $^{28-30}$. Existe consenso en que estas moléculas inhiben la síntesis de proteínas y que, además, producen una lectura errónea de la información del ARN mensajero, determinando la incorporación de algunos aminoácidos incorrectos en la cadena peptídica. Según Davis BD ${ }^{8,29,30}$, el efecto bactericida final sería de carácter pleiotrópico, debido a la incorporación de algunos de estos péptidos a la membrana citoplasmática, lo que conduce a una alteración de la permeabilidad y una entrada progresiva de moléculas de aminoglucósidos al interior de la célula bacteriana, produciendo una inhibición irreversible de la actividad ribosomal y por tanto de la síntesis de proteínas. Si bien en procariontes a concentraciones terapéuticas la mayoría de los antimicrobianos aminoglucósidos son inhibidores de la síntesis proteica, a mayor concentración podrían también tener efecto sobre la síntesis de proteínas en mamíferos, probablemente mediante uniones no específicas a ribosomas y ácidos nucleicos eucarióticos ${ }^{6,7}$.

\section{Mecanismos de resistencia}

Los principales mecanismos de resistencia a los aminoglucósidos son:

- Alteración del sitio blanco. Por mutación de los genes de proteínas ribosomales o del ARN $16 \mathrm{~S}$, lo que tiene importancia clínica para estreptomicina ${ }^{6,7}$

- Reducida acumulación intracelular del compuesto. Esta disminución, principalmente observada en Pseudomonas spp y otros bacilos gramnegativos no fermentadores, se puede atribuir fundamentalmente a la impermeabilidad de la membrana externa, causada por varios factores, como son cambios en las proteínas de membrana externa, determinando un nivel de susceptibilidad intermedio a estos agentes antibacterianos ${ }^{6}$. También se ha descrito que 
en algunas mutantes existe alteración del acoplamiento de la síntesis de ATP con el transporte de electrones, produciéndose una disminución de la entrada del antimicrobiano a la bacteria por fallas en la generación de FPM ${ }^{11,31}$. Recientemente, también se ha descrito resistencia mediada por eflujo; sin embargo, la importancia clínica de este tipo de mecanismo de resistencia parece poco trascendente ${ }^{30,32,33}$.

- El tercer mecanismo, el más frecuente y ampliamente investigado, corresponde a la inactivación de los compuestos por enzimas modificantes de aminoglucósidos (EMA) ${ }^{34}$. Estas enzimas catalizan la modificación covalente de grupos aminos e hidroxilos de la molécula, generando modificaciones químicas que llevan al aminoglucósido a unirse débilmente a los ribosomas bacterianos y, por lo tanto, también afectando el ingreso del antibacteriano en la fase 2 dependiente de energía. Las EMA se dividen en 3 grupos:

- Aminoglucósido-acetiltransferasas (AAC), que acetilan grupos amino utilizando como cofactor la acetilcoenzima A. Un ejemplo es la enzima acetilante AAC(3)-II (también llamada AAC(3)$\mathrm{V)}$ que inactiva gentamicina, pero no amikacina. Otro interesante ejemplo de este tipo de enzimas es la AAC(6')-I, capaz de inactivar amikacina, pero no gentamicina. Este última EMA ha sido informada en nuestro país, con un importante incremento de cepas que la producen, posiblemente a causa del uso frecuente de este aminoglucósido ${ }^{35,49}$.

- Aminoglucósido-adeniltranferasas (AAD, actualmente designadas como ANT), enzimas conocidas también como nucleotidiltransferasas, que adenilan ciertos grupos hidroxilos

- Aminoglucósido-fosfotransferasas (APH), que también modifican los grupos hidroxilos mediante fosforilación. Estos dos tipos de enzimas utilizan nucleósidos trifosfatos, especialmente ATP, como cofactor. La clasificación de estas enzimas se vuelve más compleja si se considera el hecho que pueden ser bifuncionales y que los sitios blancos pueden ser inactivados por diferentes grupos de ellas (isoenzimas). En la mayoría de los casos y, fundamentalmente para bacilos gramnegativos, la resistencia a aminoglucósidos se debe a la acción, de al menos, una de estas enzimas ${ }^{34,35}$.

- Recientemente se ha descrito la metilación postranscripcional del ARNr, mecanismo que era conocido en aquellos microorganismos que naturalmente producían moléculas de este grupo $^{36}$. La metilación de bases involucradas en la unión entre el ARNr 16S y el aminoglu- cósido disminuye la afinidad del antibacteriano por sus sitios de unión, induciendo resistencia bacteriana. Interesantemente, este mecanismo es particularmente eficiente, ya que modifica todas las copias de ARNr $16 \mathrm{~S}$ produciendo, por tanto, un alto nivel de resistencia a un amplio espectro de representantes de esta familia. Más aún, el gen que codifica la metiltransferasa, arm A, se encontró asociado a otros genes de resistencia en un plásmido conjugativo y en el cual también se identificaron elementos transponibles, sugiriendo una importante posibilidad de diseminación entre las bacterias ${ }^{37}$.

\section{Origen genético de la resistencia a aminoglucósidos}

Las enzimas modificantes de aminoglucósidos son normalmente codificadas por elementos extracromosomales tales como plásmidos y transposones ${ }^{34,35,38}$. Esto es fundamental al considerar la potencial diseminación de estos genes de resistencia hacia cepas susceptibles. Por ejemplo, un estudio realizado por González ${ }^{39}$ en 486 cepas de Acinetobacter baumannii aisladas entre 1990 y 1998 en diferentes hospitales de Chile, reveló que la mayoría de ellas era resistente a aminoglucósidos. Trece de estas cepas fueron sometidas a experimentos de curación de plásmidos, detectándose la pérdida de un plásmido de más de $30 \mathrm{~kb}$, el que se asoció, en la mayoría de los casos, con la recuperación de susceptibilidad a amikacina, kanamicina y neomicina, sugiriendo que en este plásmido se ubicarían los genes que codifican para EMA, específicamente la combinación AAC(6')-I + APH(3'). Estos resultados concuerdan con Lambert y $\operatorname{col}^{40}$, quienes también encontraron que los genes que conferían resistencia a amikacina y kanamicina se encontraban en un plásmido. Se ha informado, además, que la diseminación de estos determinantes de resistencia sería inter especie y que estaría favorecida por la presión selectiva que se ejerce en el ambiente hospitalario, por el constante uso de estos compuestos antibacterianos ${ }^{41,42}$.

En la última década sin embargo, se ha detectado la presencia de nuevos elementos genéticos que participarían en la resistencia bacteriana. Se trata de cassettes genéticos que albergan genes que codifican resistencia a antibacterianos ${ }^{43,44}$. Los cassettes se encuentran asociados a integrones, los cuales son capaces de captar estos determinantes de resistencia gracias a la acción de una recombinasa específica de sitio (integrasa) y proporcionarles el o los promotores necesarios para su expresión ${ }^{45,46}$. Hasta el momento, se ha infor- 
mado de la existencia de cuatro clases de integrones en bacterias gramnegativas, las que se diferencian por la homología que presenta la integrasa en su secuencia aminoacídica. El integrón más frecuentemente encontrado en aislamientos de origen clínico es el de clase 1 , se caracteriza por poseer un extremo 5' conservado que contiene el gen de la integrasa (intI) y el sitio de recombinación específica de sitio (attI). Además esta clase de integrones posee un extremo 3' conservado que está conformado por genes que otorgan resistencia a compuestos de amonio cuaternario y desinfectantes ( $q a c E D 1)$, sulfonamidas (sul 1) y un marco de lectura abierto (orf5), del que se desconoce su producto y función. Entre ambas regiones se encuentra una zona variable, que es el lugar en donde se integran los cassettes genéticos de resistencia (Figura 2) ${ }^{46,47}$.

En nuestro medio se han realizado varios estudios sobre los tipos de integrones más frecuentemente encontrados en distintas bacterias gramnegativas; así en A. baumannii el integrón clase 2 es el más frecuente; mientras que en las enterobacterias de origen hospitalario, la clase 1 es la predominante ${ }^{48,49}$. Recientemente, se ha descrito integrones clase 1 y clase 2 en cepas de Shigella flexnneri $^{50}$. Muchos de estos integrones albergan cassettes genéticos de resistencia a aminoglucósidos. En el ámbito internacional, MartínezFeijo y $\mathrm{col}^{51}$, describieron que todos los aislamientos de enterobacterias (E. coli, Klebsiella oxytoca, Enterobacter cloacae, E. aerogenes,
Proteus mirabilis y Serratia marcescens) contenían, al menos, un cassette genético de resistencia a aminoglucósidos.

La expresión de los genes de resistencia presentes en cassettes genéticos asociados a integrones está modulada por varios factores, entre éstos: ubicación a nivel cromosómico o plasmídico y el número de copias de éstos. También la expresión de estos genes puede estar influenciada por la posición del inserto, es decir, como los cassettes genéticos carecen de un promotor propio, dependerá de la proximidad al promotor del integrón el nivel de la expresión del gen en cuestión ${ }^{43,45}$. Collis y Hall ${ }^{46}$, diseñaron un constructo, en donde dispusieron de un integrón con 3 cassettes de resistencia, 2 de ellos codificaban para la resistencia a aminoglucósidos. Las bacterias que poseían el plásmido (con el integrón) que contenía como primer inserto el gen aacl, presentaron una $\mathrm{CIM}_{50}$ de 45 a $55 \mu \mathrm{g} / \mathrm{ml}$ para gentamicina, estos niveles de resistencia se redujeron 4 a 5 veces cuando este cassette se ubicó detrás del cassette aadA2. La disminución en los niveles de susceptibilidad llegó a 20 veces cuando existía además alguna mutación en la región promotora del integrón. Por lo anterior, una cepa puede aparecer fenotípicamente como susceptible, pero en realidad ser genotípicamente resistente, debido, entre múltiples otros factores, a la posición del cassette genético. De hecho, se ha postulado que la utilización de un determinado antibacteriano puede llevar al reordenamiento de

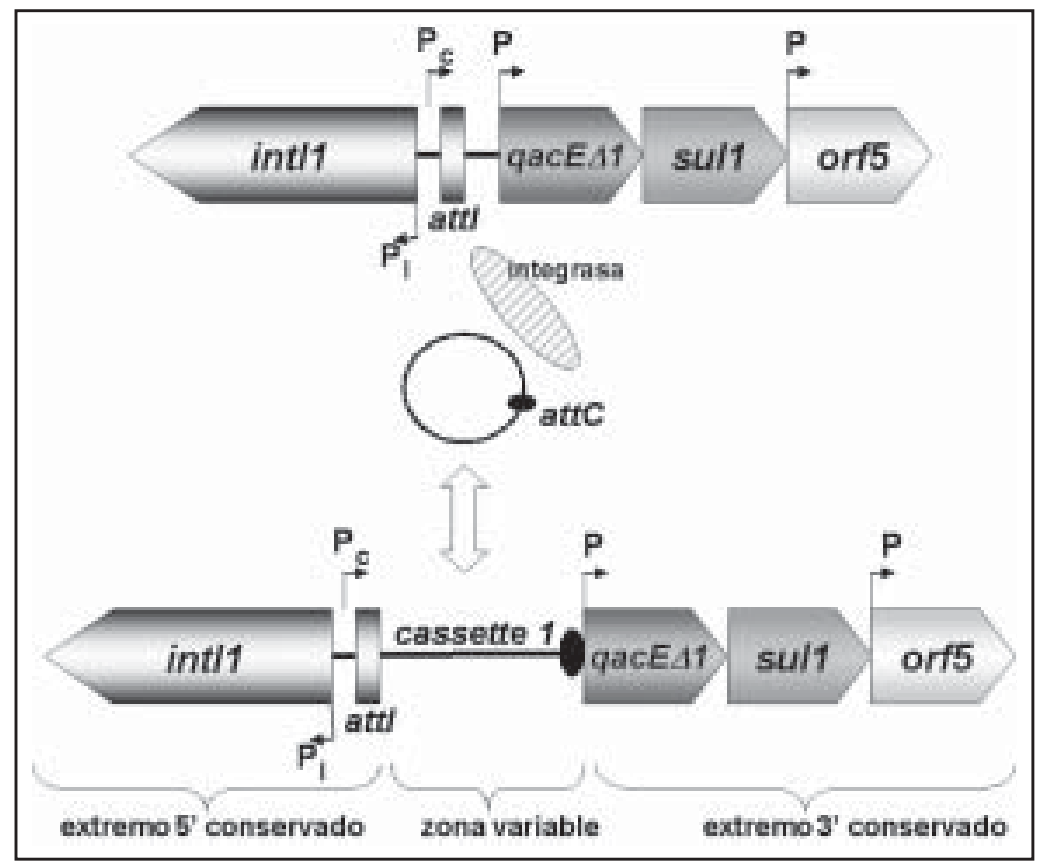

Figura 2. Estructura de integrón clase 1conteniendo cassettes genéticos de resistencia a aminoglucósidos. 
los cassettes genéticos que confieren resistencia para dicho compuesto, acercándolo al promotor del integrón ${ }^{45,46}$.

\section{Perspectiva}

En el contexto de un incremento sorprendente de nuevos patógenos resistentes, nuevos mecanismos de resistencia y de cambios epidemiológicos asociados, en comparación con una progresiva disminución de la capacidad para sintetizar nuevos agentes antibacterianos ${ }^{52-54}$, los aminoglucósidos no constituyen la excepción; sin embargo, durante los últimos años se han descrito algunas noticias favorables. Destaca el uso cada vez más frecuente y aceptado del uso de estos agentes en monodosis en infecciones causadas por bacilos gramnegativos ${ }^{55-57}$; la síntesis y uso clínico de arbekacina, molécula derivada de dibekacina que ha demostrado una interesante actividad sobre cepas de Staphylococcus aureus resistentes a meticilina, habiéndose incluso evidenciado sinergia al asociarla con vancomicina ${ }^{58,59}$ y la alternativa teórica para el uso de aminoglucósidos asociados a liposomas para aumentar su penetración intracelular ${ }^{60}$.

\section{Resumen}

Los antimicrobianos aminoglucósidos-aminociclitoles constituyen una de las familias de agentes antibacterianos de mayor actividad sobre bacilos gramnegativos aeróbicos. Estos compuestos están característicamente formados por la combinación de un alcohol cíclico aminado (aminociclitol) y aminoazúcares (aminoglucósidos) unidos por enlaces glucosídicos. La potente actividad bactericida de estos compuestos parece no sólo explicarse por su capacidad de inhibición de la síntesis proteica, sino que también por un efecto sumatorio y pleiotrópico que altera la permeabilidad de la membrana citoplasmática. La penetración de estos antibacterianos en células bacterianas ocurre mediante tres fases bien definidas, siendo las dos últimas dependientes de la fuerza protón motriz (FPM). Este hecho explica la ausencia de actividad de estos compuestos sobre bacterias anaeróbicas.

La resistencia bacteriana a este grupo de antibacterianos se debe, principalmente, a la producción de enzimas modificantes de aminoglucósidos. Estas enzimas son normalmente codificadas por elementos extracromosomales tales como plásmidos y transposones. Sin embargo, se han identificados nuevos mecanismos y elementos genéticos que participarían en los fenómenos de resistencia. Recientemente se ha descrito la metilación de bases involucradas en la unión entre el ARN 16S y el aminoglucósido, lo que implicaría un nuevo mecanismo de resistencia contra esta familia de antimicrobianos.
Por otra parte, los cassettes genéticos adquieren una creciente importancia ya que albergan genes de resistencia a múltiples familias de antibacterianos, entre ellos, los aminoglucósidos-aminociclitoles. Estos cassettes genéticos se encuentran asociados a integrones, los cuales son capaces de captar estos determinantes de resistencia y expresarlos.

\section{Bibliografía}

1.- Gilbert D N. Aminoglycosides. En Mandell, Douglas and Bennett's Principles and Practice of Infectious Diseases. Mandell GL, Bennett JE and Dolin R. eds., $4^{\text {th }}$ ed. Churchill Livingstone, New York, N.Y. 2000; pp: 307-35.

2.- Waksman SA. Present status of streptomycin therapy. Lancet 1946; 66: 77-8.

3.- Mackaness GB. The action of drugs on intracellular tubercle bacilli. J Pathol Bacteriol 1952. 64: 429-46.

4.- Palomino J, Pachón J. Aminoglucósidos. Enf Infecc Microbiol Clin 2003; 21: 105-15.

5.- Chambers HF, Sande MA. Antimicrobial agents: the aminoglycosides. In J.G. Hardman, L.E. Limbird, P.B. Molinoff, R.W. Ruddon and A. Goodman Gilman ed, The Pharmacological Basis of Therapeutics. McGrawHill, New York, N.Y. 1995. pp: 103-1021.

6.- Mingeot-Leclercq M, Glupczynski Y, Tulkens PM. Aminoglycosides: Activity and resistance. Antimicrob Agents Chemother 1999; 43: 727-37.

7.- KOTRA LP, HADDAD J, MOBASHERY S. Aminoglycosides: Perspectives on mechanism of action and resistance and strategies to counter resistance. Antimicrob Agents Chemother 2000; 44: 3249-56.

8.- Davis BD. Mechanism of bactericidal action of aminoglycosides. Microbiol Rev 1987; 51: 341-50.

9.- Davies JE. Aminoglycosides-aminocyclitol antibiotics and their modifying enzymes. In: Lorian V, Ed. Antibiotics in Laboratory Medicine. Baltimore USA: Williams \& Wilkins. 1980. pp: 474-89.

10.- Mingeot-Leclercq M, Tulkens PM. Aminoglycosides: Nephrotoxicity. Antimicrob Agents Chemother 1999; 43: 1003-12.

11.- Mella S, García A, Aguilera Le., Zemelman R. Antibióticos aminoglicósidos. Agrupación según su estructura química y actualización sobre algunas de sus propiedades. Acta Microbiol 1993; 4: 5-13

12.- Zhanel Gg, Craig WA. Pharmacokinetic contributions to postantibiotic effects. Focus on aminoglycosides. Clin Pharmacokinet 1994; 27: 377-99.

13.- Bactericidal inhibitors of protein synthesis. The aminoglycosides. In: Scholar EM, Pratt WB. (Eds). The Antimicrobial drugs. Second Edition. Oxford University Press, New York, USA 2000; 127-58.

14.- Pancoast SJ. Aminoglycoside antibiotics in clinical use. Med Clin North Am 1988; 72: 581-612.

15.- Edson Rs, Terrel CL. The aminoglycosides. Mayo Clin Proc 1999; 74: 519-28.

16.- Rinehart KL., Jr. Comparative chemistry of the aminoglycoside and aminocyclitol antibiotics. J Infect Dis 1969; 119: 345-50.

17.- Benveniste R, Davies J. Structure-activity relationship among the aminoglycoside antibiotics: role of hidroxyl and amino groups. Antimicrob Agents Chemother 1973; 4: 402-9. 
18.- Hayashi Sf, Norcia Lj, Seibel Sb, Silvia AM. Structureactivity relationship of hygromycin $\mathrm{A}$ and its analogs: protein synthesis inhibition activity in a cell free system. J Antibiot 1997; 50: 514-21.

19.- Phillips I, Shannon KP. Aminoglycosides and aminocyclitols. In O'Grady F, Lambert HP, Finch RG, Greenwood D. Antibiotic and Chemotherapy. Seven Ed. Churchill Livingstone, New York, Edimburgh. 1997. pp: 363-8.

20.- Jackson GE, Lolans VT, Daikos GL. The inductive role of ionic binding in the bactericidal and postexposure effects of aminoglycoside antibiotics with implications for dosing. J Infect Dis 1990; 162: 40813.

21.- Murray BE. New aspects of antimicrobial resistance and the resulting therapeutic dilemmas. J Infect Dis 1991; 163: 1185-94.

22.- Hancock RE, Farmer SW, LI ZS, Poole K. Interaction of aminoglycosides with the outer membranes and purified lipopolysaccharide and $\mathrm{OmpF}$ porin of Escherichia coli. 1991. Antimicrob Agents Chemother 35: 1309-14.

23.- Vaara M. Agents that increase the permeability of the outer membrane. Microbiol Rev 1992; 56: 395-411.

24.- Chung L, Kaloyanides G, McDaniel R, McLaughlin A, McLaughlin S. Interaction of gentamicin and spermine with bilayer membranes containing negatively-charged phospholipids. Biochemistry 1985; 24: 442-52.

25.- Xiong Yq, Caillon J, Drugeon H, Potel G, Baron D. Influence of $\mathrm{pH}$ on adaptive resistance of Pseudomonas aeruginosa to aminoglycosides and their postantibiotic effects. Antimicrob Agents Chemother 1996; 40: 36-39.

26.- Hancock REW. Aminoglycoside uptake and mode of action with especial reference to streptomycin and gentamycin. II. Effects of aminoglycosides on cells. J Antimicrob Chemother 1981; 8: 429-45.

27.- Zemelman R, Bello H, Vivas ME, Mondaca MA. Un método simple para estudiar la cinética de acción bactericida de sustancias antibacterianas. Acta Microbiol 1988; 1:33-9.

28.- Davis BD. Non-specific membrane permeability and aminoglycoside action. J Antimicrob Chemother 1989; 24:77-8.

29.- Davis BD, Chen LL, Tai PC. Misread protein creates membrane channels: an essential step in the bactericidal action of aminoglycosides. Proc Natl Acad Sci USA 1986; 83: 6164-8.

30.- Wyka Ma, St John AC. Effects of production of abnormal proteins on the rate of killing of Escherichia coli by streptomycin. Antimicrob Agents Chemother 1990; 34: 534-8.

31.- Taber HW, Mueller JP, Miller PF, Arrow A. Bacterial uptake of aminoglycoside antibiotics. Microbiol Rev 1987; 51: 439-57.

32.- Moore RA, Deshazer D, Reckseidler S, Weissman A, Woods DE. Efflux-mediated aminoglycoside and macrolide resistance in Burkholderia pseudomallei. Antimicrob Agents Chemother 1999; 43: 465-70.

33.- Magnet S, Courvalin P, Lambert T. Resistancenodulation-cell division-type efflux pump involved in aminoglycoside resistance Acinetobacter baumannii strain BM 4454. Antimicrob Agents Chemother 2001; 45: $3375-80$.

34.- Shaw KJ, Rather PN, Hare RS, Miller GH. Molecular genetics of aminoglycoside resistance genes and familial relationships of the aminoglycoside-modifying enzymes. Microbiol Rev 1993; 57: 138-63.
35.- Del Solar E, García A, Bello H, Domínguez M, González G, Zemelman R. Mecanismos enzimáticos de resistencia a antibióticos aminoglicósidos en bacilos Gram negativos de hospitales chilenos. Rev Méd Chile 1995; 123: 293-7.

36.- Beauclerk Aa, Cundliffe E. Sites of action of two ribosomal RNA methylases responsible for resistance to aminoglycosides. J Mol Biol 1987; 193: 661-71.

37.- Galimand M, Courvalin P, Lambert T. Plasmidmediated high-level resistance to aminoglucosides in Enterobacteriaceae due to $16 \mathrm{~S}$ rRNA methylation. Antimicrob Agents Chemother 2003; 47: 2565-71.

38.- Davies J, Wright GD. Bacterial resistance to aminoglycoside antibiotics. Trends Microbiol 1997; 5: $234-40$

39.- González G. Rol de integrones y cassettes genéticos en la resistencia de Acinetobacter baumannii a antibióticos aminoglicósidos. 2002. Tesis para optar al grado de Doctor en Ciencias Biológicas. Escuela de Graduados Universidad de Concepción

40.- Lambert T, Gerbaud G, Courvalin P. Transferable amikacina resistance in Acinetobacter spp. due a new type of 3'-aminoglycoside phosphotransferase. Antimicrob Agents Chemother 1988; 32: 15-9.

41.- Bush K, Miller GH. Bacterial enzymatic resistance: $\beta$ lactamases and aminoglycoside-modifying enzymes. Curr Opin Microbiol 1998; 1: 509-15.

42.- Zembower TR, Noskin GA, Postelnick MJ, Nguyen C, Peterson LR. The utility of aminoglycoside in an era of emerging drug resistance. Int $\mathbf{J}$ Antimicrob Agents 1998; 10: 95-105.

43.- Recchia G, Hall R. Gene cassettes: a new class of mobile elements. Microbiol 1995; 141: 3015-27.

44.- Bennett PM. Integrons and gene cassettes: a genetic construction kit for bacteria. J Antimicrob Chemother 1999; 43: 1-4.

45.- Stokes HW, Hall RM. A novel family of potentially mobile DNA elements encoding site-specific geneintegration functions: integrons. Mol Microbiol 1989; 3: $1669-83$.

46.- Collis C, Hall R. Expresion of antibiotic resistance genes in the integrated cassettes of integrons. Antimicrob Agents Chemother 1995; 39: 155-62.

47.- Manning P, Clark C, Focareta T. Gene capture in Vibrio cholerae. Trends Microbiol 1999; 7: 93-5.

48.- Ramírez C, Pino C, González G, Bello H, Domínguez $\mathrm{M}$, Mella $\mathrm{S}$, et al. Presencia de integrones y su relación con la resistencia a cefalosporinas de tercera generación en cepas de Acinetobacter baumannii de origen nosocomial. Rev Méd Chile 2000; 128: 863-7.

49.- Reyes A, Bello H, Domínguez M, Mella S, Zemelman R, González G. Prevalence and types of class 1 integrons in aminoglycoside-resistant Enterobacteriaceae from several chilean hospitals. J Antimicrob Chemother 2003; 51: 317-21.

50.- Muñoz J, Bello H, Domínguez M, Mella S, Zemelman $\mathrm{R}$, González G. Integrones y cassettes genéticos de resistencia a antimicrobianos en cepas de Shigella flexneri. Rev Méd Chile 2003; 131: 727-33.

51.- Martinez-Freijo P, Fluit A, Schmitz Fj, Verhoef J, Jones M. Many class I integrons comprise distinct stable structures occuring in different species of Enterobacteriaceae isolated from widespread geographic regions in Europe. Antimicrob Agents Chemother 1999; 43: 686-9.

52.- Lorber B. Changing patterns of infectious diseases. Am J Med 1988; 84: 569-78.

53.- Moellering RC. Linezolid: the first oxazolidinone 
antimicrobial. Ann Intern Med 2003; 138: 135-42.

54.- Neu HC. The crisis of antibiotic resistance. Science 1992; 257: 1064-73.

55.- Ali MZ, Goetz MB. A meta-analysis of the relativeefficacy and toxicity of single daily dosing versus multiple daily dosing of aminoglycosides. Clin Infect Dis 1997; 24: 796-809.

56.- Hatala R, Dinh T, Cook DJ. Single daily dosing of aminoglycosides in immunocompromised adults: A systematic review. Clin Infect Dis 1997; 24: 810-15.

57.- Munckhof $\mathrm{Wj}$, Grayson Ml, TurnidgE JD. A metaanalysis of studies on the safety and efficacy of aminoglycosides given either once daily or as divided doses. J Antimicrob Chemother 1996; 37: 645-63.
58.- You I, Kariyama R, Zervos Mj, Kumon H, Chow JW. In-vitro activity of arbekacin alone and in combination with vancomycin against gentamicin-and methicillin-resistant Staphylococcus aureus. Diagnos Microbiol Infect Dis 2000; 36: 37-41.

59.- Akins RL, Rybak MJ. In vitro activities of daptomycin, arbekacin, vancomycin, and gentamicin alone and/or in combination against glycopeptide intermediate-resistant Staphylococcus aureus in an infection model. Antimicrob Agents Chemother 2000; 44: $1925-9$

60.- Kawlowsky Ja, Zhanel GG. Concepts of the use of liposomal antimicrobial agents: Applications for aminoglycosides. Clin Infect Dis 1992; 15: 654-67.

Correspondencia a:

Sergio Mella Montecinos

pignatio@vtr.net 